\title{
Main Functions and Realization Paths of First Hand Historical Materials in History Teaching of High School
}

\author{
Yang Jiang ${ }^{1, \text { a }}$ \\ ${ }^{1}$ College of History and Culture, Northwest Normal University, Lanzhou, 730000, China \\ ${ }^{\mathrm{a} e m a i l}$
}

Keywords: First hand historical materials, History teaching, Three-dimensional target, Methods innovation

\begin{abstract}
The application of the first hand historical materials in history teaching of high school is conducive to enhancing learning interest, cultivating autonomous learning ability, erecting correct emotional attitude values and realizing the innovation and reform of teaching methods. We should expand Historical Materials resources and arrange the pre-class work reasonably to cultivate the ability of apply Historical Materials before class. We should transform the teaching directions to construct a study model oriented by problem-solving in the class. We should build a diversified system of teaching evaluation, which needs the opinions mainly from the students. These are the three important paths of the applications of first hand historical materials.
\end{abstract}

The importance of historical data teaching in senior high school history teaching has become a consensus in academia. But in the process of historical teaching often ignore the difference between the first and second-hand data sources, found in such a historical era, an important problem of how to use the first-hand data in high school history teaching process, enhance students' interest in learning, worthy of cultivation of historical thinking and change of learning methods, improve the humanistic quality of academic thinking.

\section{Current Situation and Condition of Applications of First Hand Historical Materials in History Teaching of High School}

Since the twentieth Century, especially since the reform and opening to the outside world, a great deal of archaeological discoveries and new historical materials have played an important role in promoting the development of historiography. Study of contemporary China history is gradually emerging from the traditional historiography mainly depends on the document. First hand data not only expand the field of vision and the method of historical research, but also promote the development of teaching materials.

From the current situation of history teaching in high school, most teachers still carry out teaching activities on the basis of secondary historical data. Compared with the second-hand ones, first hand data not only novel form, rich in content, broad geographical, time span is included from ancient legends and modern times throughout history stage. Most importantly, these historical data are the real reflection and record of the social life at that time, and have the objectivity and authenticity that the second hand historical data cannot compare with. The use of first-hand teaching of historical materials must also take into account the cognitive and receptive capacity of students and the restrictions on the school running conditions. In the process of learning history, historical knowledge and historical analysis ability is a unity, after junior high school stage of learning, high school students have to China and world history development have a relatively clear understanding and have a certain ability to read and analyze historical data. The application of computer multimedia technology in teaching, provides a variety of interactive integrated information processing of various characters, pictures, images and so on the conditions for the senior high school history teacher, and 
play its characteristics of illustrations, vivid and flexible presentation of teaching content, creating a good teaching site.

\section{Main Functions of First Hand Historical Materials in History Teaching of High School}

The First Hand Historical Materials are Conductive to Innovating Teaching Methods and Cultivating Autonomous Learning Ability. First-hand data include not only new unearthed documents and historical materials, but also a large number of unearthed historical relics, portrait stones and other historical materials and images. Among them, image historical data is an important link in our study of history, research history and Deconstruction of history. With its simple, intuitive and visual impact, it has the teaching advantages of text materials. The first-hand data is not only the construction of an important basis for the interpretation of history and history, culture is the starting point of historical thinking ability, cultivation of historical thinking ability should be based on objective materials, otherwise, its history will deviate from the real facts. And the history of the teaching material is the historical thinking result of the compiling of the textbook. The student's study of the teaching material is just the inheritance and memory of the existing thinking results. When the students face these transcendental conclusions, they see only the historical facts and conclusions presented by the predecessors. It can not only arouse students' thinking operation, but also make students in memorizing historical facts and historical knowledge". But through collecting and summing up of first-hand data, make student information carrying capacity can not only break the textbooks inherent, but also broaden the horizons and knowledge, improve the knowledge structure and natural history from the past passive acceptance of teachers and textbooks become through their own collection of historical materials to summarize views. Improve the ability to interpret and apply historical materials and to analyze and study historical figures, historical issues and historical phenomena.

The First Hand Historical Materials are Conductive to Cultivating Correct Emotional Attitude Values. The reform of history curriculum aims to cultivate the students' right emotions, attitudes and values, but the establishment of values often requires personal experience and experience. First hand historical data is more convincing and authoritative because of its objectivity and authenticity. In the course of teaching "the opening of the new route", many students question the size of the Zheng He fleet, as well as the historical records, as they sigh over the great spirit of exploration by the western navigator. For this reason, the author shows the latest achievements of archaeological excavation of Nanjing He Cheng Bao shipyard site. In the face of irrefutable evidence "first-hand data, before the students not only to dispel the doubts, by the great wisdom of the working people in ancient China created by, and through the reduction of historical scenes, let the students in the experience of historical authenticity, in-depth understanding of history, judge the reasonable value of the history of things that contributed to the emotion sublimation.

\section{Realization Paths of First Hand Historical Materials in History Teaching of High School}

Preparation before Class. In the context of history curriculum reform in senior high school, the preparation course of history teaching in senior high school has gone beyond the previous summary of teaching content, the simple arrangement of teaching process and the analysis and mastering of test center knowledge. It requires teachers to start from the concept of new curriculum, to train students' learning ability and learning methods, and to correct their emotions, attitudes and values. Especially in the process of using first-hand historical materials to carry out teaching activities, we need to do adequate preparation before class, and sum up the following aspects.

With the arrival of the information age, new historical concepts, new methods and new historical materials emerge in an endless stream, the development of the subject of history is speeding up, and the internal requirements are constantly improved. The ready-made knowledge of books is no longer enough for "static braking", and a higher demand for people's creative thinking and ability. Knowledge is no longer a ready-made answer in books. This requires teachers to learn in daily life 
and in the process of planning to acquire new knowledge, absorb new ideas, new ways to master, understand and follow the latest academic developments, strengthen the theory of history learning, expand knowledge, enhance the professional quality. Make full use of the Internet and library resources in the preparation process, such as the Wuhan University and Chinese network, the official website of National Museum, Chinese cultural network, CALIS interlibrary loan and document delivery service network, "Journal of archaeology", "Qin Bamboo Slips," collection "Dunhuang literature classification school record issue" "China plexus, modern rare historical collections" other books and websites can provide comprehensive and authoritative first-hand information for teachers.

Take the way of collective preparation in preparing process, through the teaching team to strengthen the research on the first-hand data and promote the teaching content and teaching method reform, realize the first-hand data resource sharing, and establish the "Historical Library in the process of accumulation". This is not only convenient for other teachers' teaching activities, to ensure the use of first-hand historical data teaching scientifically and effectively and broaden the sources of information, reduce the first-hand data collection pressure, improve the preparation efficiency.

In the course of preparing lessons, teachers should also arrange the tasks before class in combination with textbooks and teaching objectives, so as to cultivate students' ability to collect first-hand first-hand historical data. To "establish" unified and centralized system of the Qin Dynasty as an example, the author arranged before teaching students to use the weekend time to visit the Museum of the city of Jincheng, to watch the battle of Changping cultural relics exhibition, collection of Qin Dynasty in the unification process of the historical and cultural relics and visited the site of the battle of Changping, first hand historical materials. At the same time, instruct the students to classify and file the collected historical data, to interpret and analyze the historical data, to delete the contents irrelevant to the teaching contents, and to help the students remove the text obstacles in the historical data. The first-hand data in the clear historical information to further deepen the connotation of mining historical data, historical understanding, and on the first-hand data summary and conclusion, such as the real materials into images, paintings, text into graphics and charts, to cultivate students' summarizing ability and writing ability.

Teaching in Class. Some teachers still focus on how to better serve their own teaching process in the process of using the first-hand historical materials for teaching activities, so as to achieve the preset teaching objectives. Its teaching routine is either to replace or supplement readings in textbooks with a large amount of extracurricular material so that students can accept certain proven points of view." Obviously, this is not the goal of teaching students' ability to obtain historical information from various sources and to recognize historical knowledge based on historical data. In the final analysis, this phenomenon still occurs because teachers cannot get rid of the inherent thought of teacher standard. Therefore, in the process of using first-hand historical data, teachers should begin to train the students' ability goals first, from the former teacher standard to the convenience of teaching and to the students' "learning".

Refers to the teachers to guide students to reflect on a historical problem inquiry model oriented to problems, thus put forward the problems and problem oriented, guide students through collecting and summarizing, studying historical data to solve the problem, with the problem of built a bridge between students and knowledge, and make the students always in learning activities center. It is an effective way to carry out inquiry learning by using first-hand teaching of historical materials. This approach allows students to break through the existing materials and perspectives of the textbooks, thus allowing students to experience a problem as a historian- collecting historical data summarizing the process.

The first-hand historical data contain a wide range and involve all aspects of the historical development process. In the teaching activities, the historical data collected by the teachers and students are bound to be different because of different knowledge structures and information channels. Combing the complicated and diverse historical data can help students understand the complexity and diversity of historical development and appreciate the richness and variety of history. But the development of history is not haphazard, but traceable. Therefore, in the process of teaching requires teachers to pay attention to the use of historical materialism, summarized historical 
development between regional and transverse longitudinal time of causality, the first-hand data in a broader historical background analysis, the cultivation of students' ability to see the essence of the phenomenon through the understanding of the law of historical development characteristics.

Reflection after Class. The historical data is not equivalent to the fact that the materials in the process of circulation, thus there are errors, omissions and other phenomena. Especially in the use of the Internet to find historical data, we should pay more attention to verify the source of historical data and the original source. This requires teachers to grasp the ability to distinguish and identify the historical materials, and to learn the historical materials which are closely related to the teaching, and can be fully integrated with the teaching materials to arouse the enthusiasm of the students.

Full, detailed and varied first-hand historical data, of course, can improve the interest in learning and enliven the classroom atmosphere, but also take into account the content of historical materials and limited classroom teaching time and the burden of students. In view of this problem, we can guide students to study historical data through the establishment of group discussion and division of labor and cooperation, and form a cooperative inquiry learning model which takes root historical data, joint study and dialectical analysis.

The use of first-hand historical data for high school history teaching, to achieve the teaching philosophy, teaching methods, learning methods change, and promote teachers to establish a student evaluation as the main body of a diversified teaching evaluation system. This evaluation system should break through the past, and simply change the examination results to the standard of the students' learning ability and values. We should pay attention to the improvement of students' interest in learning through the teaching of first-hand historical data, the degree of students' participation in the learning process, the students' ability to sum up the historical data, and the cultivation of correct attitudes and values. These factors are not as easy to achieve quantitative indicators in the short run, but they will play an important role in the process of students' learning and growth.

\section{Conclusion}

In a word, the rapid rise of the Chinese nation has given new tasks and connotations to the history education in the new era. It requires us not only to recall the glorious history, but also to guide the students to shoulder the mission of building the Chinese dream. The application of first-hand historical data in senior high school history teaching should highlight the key role, and also be an indispensable part of the current core literacy training target.

\section{References}

[1] Zhang Qiusheng, On Inadvertently Retained Historical Materials and Historical Research [J]. Journal of Sichuan Normal University (Social Sciences Edition), 2014, 41(5): 96-103.

[2] Gong Yingyan. The Study on the Primary Historical Materials on the Voyage of Ferdinand Magellan [J]. Historiography Quarterly, 2011(3): 78-84+159.

[3] Nie Peng, Study on the Application of Historical Materials in Middle School History Teaching [J]. Journal of Guizhou Education University, 2016, 32(5): 101-104.

[4] Liu Baohong, A Research on Primary Historical Material-Based Mathematical Education and Its Application [J]. Journal of Higher Education Research, 2016, 39(3): 84-88. 